\title{
Oceanography Online
}

STEP BY STEP, The Oceanography Society is improving access to its magazine. In 2004, TOS started posting pdf files of Oceanography roughly three months after publication. Over time, the online archive grew as more issues of Oceanography were published. This past June saw a giant leap in access through the scanning and posting of all back issues of Oceanography. Most recently, a search function was added that permits you to search within the articles. Go to the online archive (www.tos.org/oceanography/issues/archive.html) and check it out.

From the start, TOS has been committed to "free access" to online issues of Oceanography. The pages are not password protected, so anyone can view and print an article, regardless of TOS membership. The magazine does not charge authors for this privilege, unlike most other free- or open-access journals.
Oceanography also provides low-resolution pdfs to authors free of charge upon publication of an issue.

Providing this level of access and service comes at a real cost to TOS, however. If you haven't already, please renew your TOS membership now, and please encourage even one more colleague or student to join. Membership dues ensure continued access to Oceanography for everyone, and also support publication of additional features such as Hands-On Oceanography.

As always, I encourage input into how we can improve Oceanography. Please send me your comments.

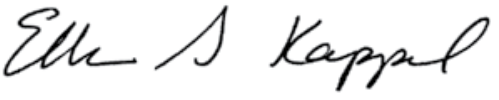

ELLEN S. KAPPEL, EDITOR Announcing the Oceanography

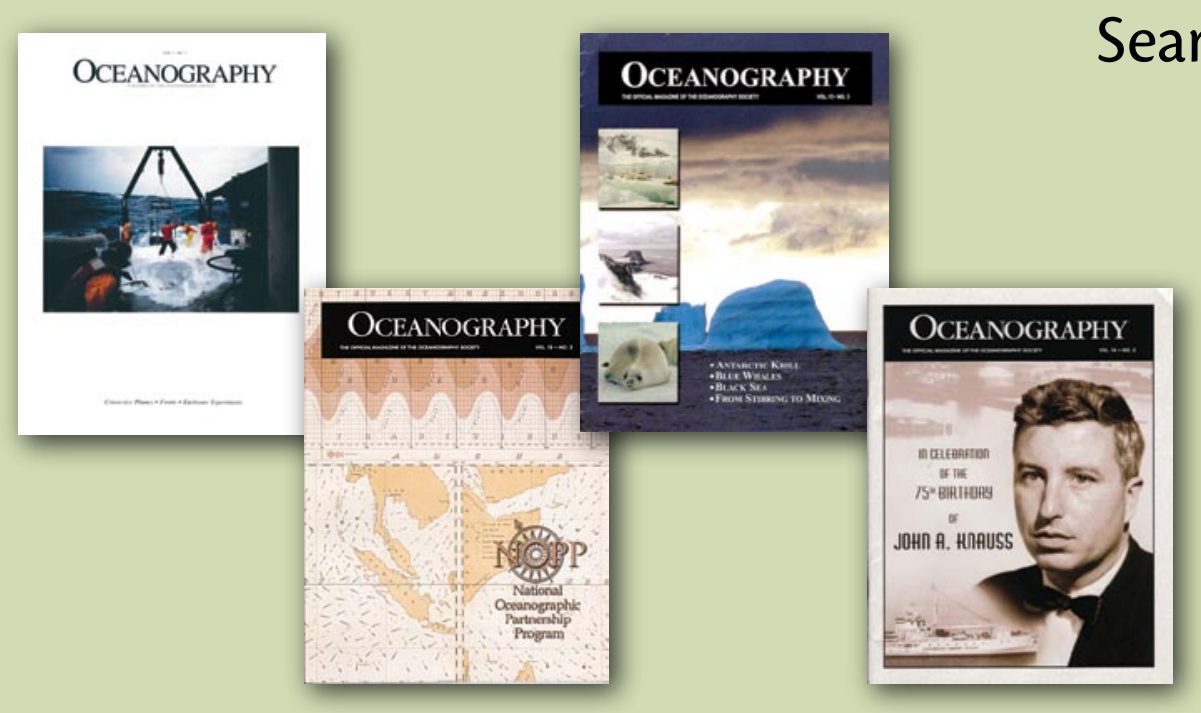

\author{
The entire collection of \\ Oceanography articles is now \\ available in a searchable online \\ archive. Check it out at: \\ www.tos.org/oceanography/ \\ issues/archive.html
}

